Diabetologia 10, $581-588$ (1974)

(C) by Springer-Verlag 1974

\title{
Epidemiology of Chinese Hamsters and Preliminary Evidence for Genetic Heterogeneity of Diabetes
}

\author{
G.C. Gerritsen, M.A. Johnson, M.G. Soret and J.R. Schultz \\ Pharmaceutical Research and Development, The Upjohn Company, Kalamazoo, MI, USA
}

\begin{abstract}
Summary. Two populations of Chinese hamsters have been produced. The nondiabetic population was from nondiabetic parents and the diabetic-producing population was from diabetic parents. Both populations had fixed reproducible genetic background since dams and sires were from inbred sublines. Sixty percent of males, but only $37 \%$ of females, born to diabetic parents developed diabetes. - Life span for males was nondiabetics $>$ mild diabetics > ketonuric diabetics. Results for females were equivocal. Mortality of severe ketonuric diabetics appears to be related to urinary tract involvement. Survival appears to be related to abnormal metabolism, not
\end{abstract}

genotype. On the basis of available data males appear more suitable for epidemiological studies on the incidence, onset, and severity of diabetes, on the evaluation of treatment of the disease, and on the longevity of diabetics. - Data on crossing diabetics from different sublines suggest that diabetic Chinese hamsters can have different genotypes.

Key words: Chinese hamster, diabetes, ketonuria, survival rates, epidemiology, urinary incontinence, genetic heterogeneity.
Epidemiological studies in man are difficult to conduct and interpret. This is particularly true of studies designed to evaluate the influence of treatments on diabetes and its complications $[1,2,3]$. Major problems encountered are sampling [4], variations in life styles, environment and nutritional habits which are difficult, if not impossible, to control. Difficulties can also be encountered with patient follow-up. A very important consideration is the relatively long life span of man.

Consequently, there are advantages to an epidemiological study concerned primarily with longevity in a spontaneously diabetic animal since life span is relatively short compared with man's and major environmental factors, as well as nutrition, can be controlled. The Chinese hamster appears to be well suited for this approach since it develops diabetes similar to man [5, 6] and has a relatively short life span, maximum 4 years, which is reduced by diabetes $[7,8]$. In addition, retinopathy $[9,10,11]$, nephropathy $[10,11,12,13]$ and neuropathy $[14,15]$ are associated with diabetes in this animal as well as histologic changes in the pancreas $[16,17]$ similar to those of man.

In view of the above considerations, a long term study in Chinese hamsters has been made, the major goal being to determine longevity in two genetically stable populations, one which produced diabetics and one which was genetically nondiabetic, as it never produced diabetics.

\section{Methods}

The populations of Chinese hamsters which have been studied had fixed reproducible genetic backgrounds. This was possible since all breeders used to produce these populations were selected from sublines which had been inbred by continuous brother-sister mating for a minimum of 8 generations so that at least $85 \%$ of their genetic material was fixed in the homozygous state [18] and could only change by mutation. One population was produced by diabetic (blood sugar $>200 \mathrm{mg} \%$ ) and the other by nondiabetic parents (blood sugar $<120 \mathrm{mg} \%$ ). Nondiabetic breeders were selected from inbred sublines which had no diabetes in their background for at least 5 generations of brothersister mating. Male and female breeders were always from different inbred sublines so that the populations studied were hybrid or outcrossed rather than inbred to avoid the possibility of inbreeding influencing longevity. In order to minimize the possiblity of an unusual genetic trait such as increased or decreased longevity in a particular litter, a male or female breeder was used only once.

Since the primary objective of this study was to obtain baseline data on the influence of diabetes on longevity of the Chinese hamster under controlled and reproducible conditions, these animals were never treated with antidiabetic agents, injected, bled or bred. After weaning, they were individually housed and fed Purina Mouse Chow ad libitum. Blood was taken from prospective breeders via the orbital sinus [19] and blood sugar determined by Auto Analyzer micromethodology [20].

A series of 10 modified glucose tolerance tests was done on each animal. These tests were started when the animals were 15 days old and continued at biweekly intervals until the animals were 5 months old. They were given $1.5 \mathrm{~g}$ of glucose $/ \mathrm{kg}$ orally and their urine tested for glucose at $0,1,2$ and $3 \mathrm{~h}$ post gavage. Starting at age 15 days, and continuing for the life of the animal, each hamster's urine was tested biweekly, by Testape ${ }^{\circledR}$, for spontaneous glucosuria. When a test for 
glucosuria was maximal, animals were also tested for ketonuria by Ketostix ${ }^{\circledR}$. Onset of diabetes or ketonuria was determined at first positive test. Starting at 15 days, body weight and food consumption were recorded at 14 day intervals for life. When possible, postmortem examinations were carried out.

All data were stored in a computer for retrieval and subsequent analysis $[21,22]$. Since specific tests and measurements had to be made on large numbers of animals on specified days (every 14 days), computer programs were developed in order to produce a printed schedule each week for data acquisition for each animal and, in addition, a list was also printed of all animals that died [21].

Table 1. Classification of Chinese hamsters by urine testing

\begin{tabular}{ll}
\hline Type & Criterion \\
\hline Diabetic & Minimum of 4 tests $>1+$ by Testape \\
Ketonuric & Minimum of 4 positive Ketostix ${ }^{\circledR}$ tests \\
Diabetic & All others \\
\hline
\end{tabular}

at similar time intervals. There was a tendency for more animals from diabetic parents to be introduced into the study earlier. Mean litter size (range 1-8) was similar in both populations. Preweaning mortality was twice as high in litters of diabetic mothers. Losses generally occurred during the first $48 \mathrm{~h}$. Since hamster mothers are cannibalistic it was not determined if pups were: a) born dead, b) neglected, or c) actively destroyed and subsequently cannibalized. Preweaning mortality correlated with large litters of 6 to 8 from nondiabetic dams but this was not true of diabetic mothers.

A higher percentage of males became diabetic than females (Fig. 1). The incidence of ketonuria, however was similar in both sexes (Fig. 2), suggesting that more diabetic females develop ketonuria than diabetic males. Although diabetes developed quite rapidly in most animals (Fig. 1), onset of ketonuria appeared to be variable especially in females. None of the 204 animals born to nondiabetic parents has developed diabetes.

Growth rates of genetically prediabetics and of nonprediabetics (hamsters with nondiabetic parents) were

Table 2. Description of the Chinese hamster populations studied

\begin{tabular}{|c|c|c|c|c|c|}
\hline \multirow{2}{*}{$\begin{array}{l}\text { Parent } \\
\text { type }\end{array}$} & \multirow{2}{*}{$\begin{array}{l}\text { Total } \\
\text { offspring }\end{array}$} & \multirow{2}{*}{$\begin{array}{l}\text { Number } \\
\text { litters }\end{array}$} & \multirow{2}{*}{$\begin{array}{l}\text { Litter } \\
\text { size }\end{array}$} & \multicolumn{2}{|c|}{ Proweaning mortality } \\
\hline & & & & Number & $\%$ of total \\
\hline Diabetic & 207 & 50 & 4.14 & 44 & 21 \\
\hline Nondiabetic & 204 & 46 & 4.43 & 22 & 11 \\
\hline
\end{tabular}

Survival and time-of-onset curves for diabetes and ketonuria were produced from the results of life table analysis [23]. Hamsters which are included in the analysis were born between March, 1970 and March, 1974. Animals which were still alive at the time of this analysis in March, 1974 are treated as withdrawing from the analysis in that time period corresponding to their age at the preceding cutoff date. The presence of withdrawals complicated the statistical analysis of survival curves since hamsters born to diabetic parents tended to enter the study earlier than hamsters with nondiabetic parents. This difficulty was circumvented by restricting the statistical comparisons to those animals which lived three years (birth date prior to March, 1971). The Wilcoxon test was used with tied observations being treated by the method of midranks [24].

Definitions of nondiabetic, diabetic and ketonuric diabetic were established on the basis of urine test results (Table $\mathbf{1}$ ).

Onset of diabetes or ketonuria was defined as the first positive Testape ${ }^{\circledR}$ or Ketostix ${ }^{\circledR}$ test.

\section{Results}

A total of 96 litters or 411 animals were born, equal numbers from each parent type (Table 2). Unfortunately, equal numbers of each type were not produced

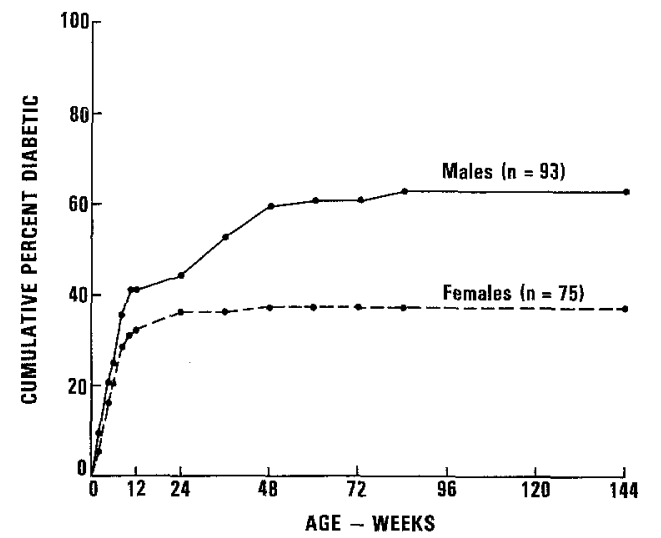

Fig. 1. Incidence and onset of diabetics in Chinese hamsters with diabetic parents

similar (Fig. 3). Ratios of food consumed in a two week interval to body weight of nonprediabeties and prediabetics were the same (Fig. 4). As expected, food consumed/g of body weight was very high until sexual maturity at 12 weeks. Diabetics consumed significantly more food per unit of body weight than nondiabetics, but their body weights were not different. It is interesting to note that females, regardless of diabetes, eat more than males on a weight basis. In addition to growth, weight and food consumption, many other 


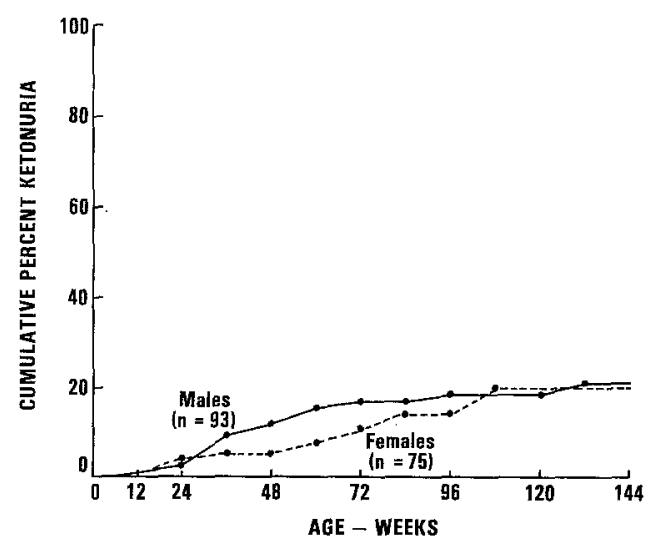

Fig. 2. Incidence and onset of ketonuria in Chinese hamsters with diabetic parents

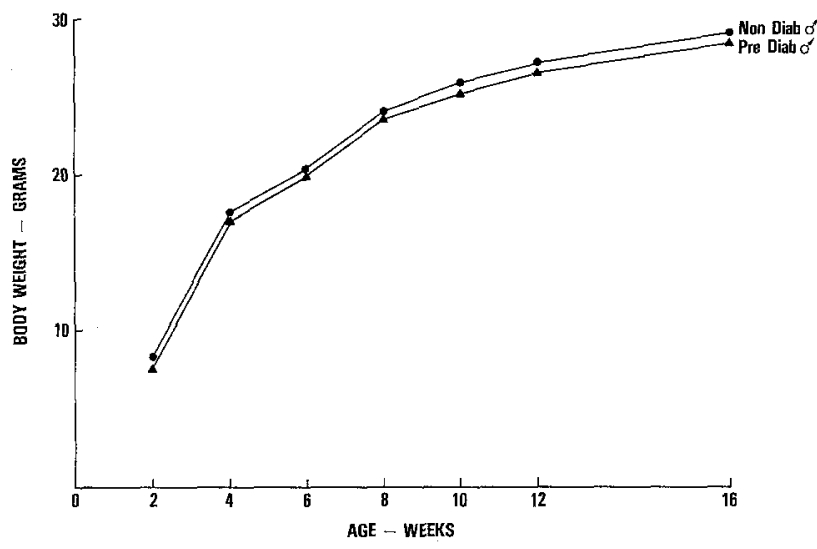

Fig. 3. Growth rates of male nonprediabetic and prediabetic Chinese hamsters

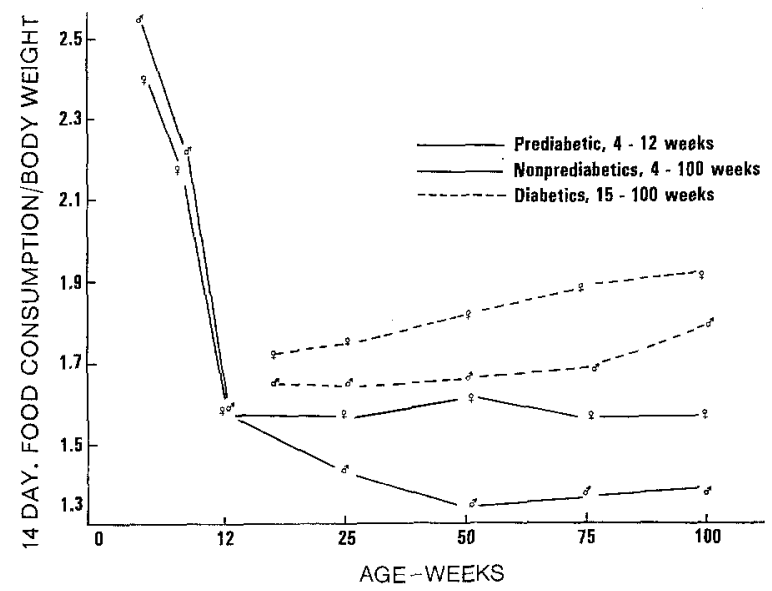

Fig. 4. Food consumption to body weight ratios of nondiabetics, prediabetic and diabetic Chinese hamsters correlations were made in an attempt to detect parameters which were predictive of diabetes. However, none of these correlations was significant (Table 3 ).

Table 3. Summary of insignificant pair-wise correlations found

\begin{tabular}{|c|c|c|}
\hline $\begin{array}{l}\text { Dam blood sugar (DBS) } \\
\text { Sire blood sugar (SBS) } \\
\text { DBS + SBS }\end{array}$ & VS & $\begin{array}{l}\text { Litter size, pre or post- } \\
\text { weaning mortality, in- } \\
\text { cidence and/or onset } \\
\text { and/or severity of dia- } \\
\text { betes, pup's birth, } 15 \\
\text { or } 24 \text { day weaning } \\
\text { weight }\end{array}$ \\
\hline $\begin{array}{l}\text { Incidence and degree of } \\
1,2,3 \mathrm{hr} \text { glucosuria after } \\
\text { glucose load. Prewean- } \\
\text { ing weight gain or Food } \\
\text { consumption during pre- } \\
\text { diabetic phase }\end{array}$ & $\mathrm{VS}$ & $\begin{array}{l}\text { Incidence and/or onset } \\
\text { and/or severity of } \\
\text { diabetes }\end{array}$ \\
\hline
\end{tabular}

Survival curves for male Chinese hamsters produced by diabetic parents suggest that ketonuric diabetics have shorter life spans than mild diabetics or nondiabetics of similar parentage (Fig. 5). Ketonuric diabetic females have a similar life span (Fig. 6). However, there is no significant difference between diabetic and nondiabetic females. Nondiabetic male Chinese hamsters from diabetic parents had somewhat shorter lifespans compared to those of nondiabetic animals born to nondiabetic parents (Fig. 7). In contrast, nondiabetic females with diabetic parents lived longer than females from nondiabetic parents (Fig. 8).

Statistical comparisons (Table 4) were based only on those animals that have survived at least 3 years, i.e. born prior to March 1971. This drastically reduced sample size in some cases. It is apparent that the numbers are insufficient to draw unequivocal conclusions and that animals which are currently one year old must be followed for an additional two years. According to this statistical analysis, ketonuric diabetes shortens life in both sexes; diabetic parents shorten the lives of their nondiabetic male, but not female, offspring.

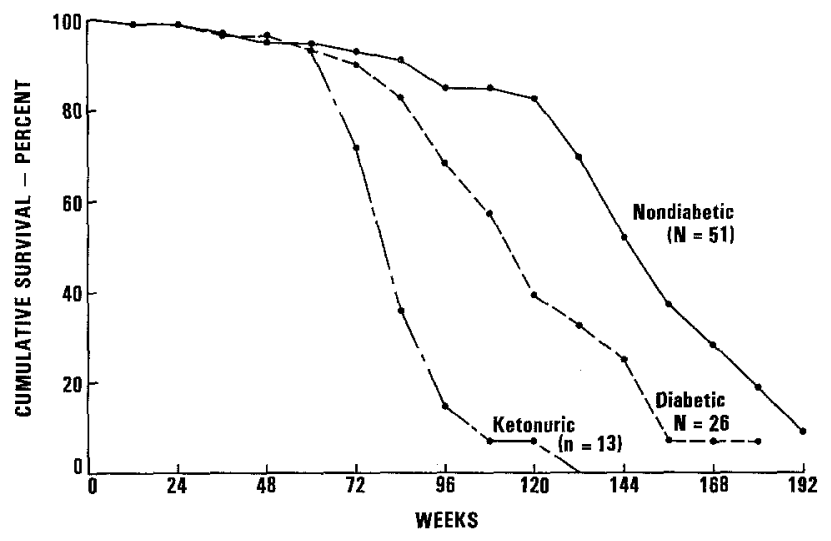

Fig. 5. Preliminary cumulative survival of male Chinese hamsters with diabetic parents 
Postmortem examinations were done on 62 of the 175 animals that died. Gross postmortem findings reveal a very high incidence $(50 \%)$ of tumors involving the liver and/or spleen and/or reproductive tract. Since these tumors were more often found in animals dying at an older age, they may account for the deaths of many older animals regardless of their metabolic states. Ketonuric hamsters died younger and showed a lower

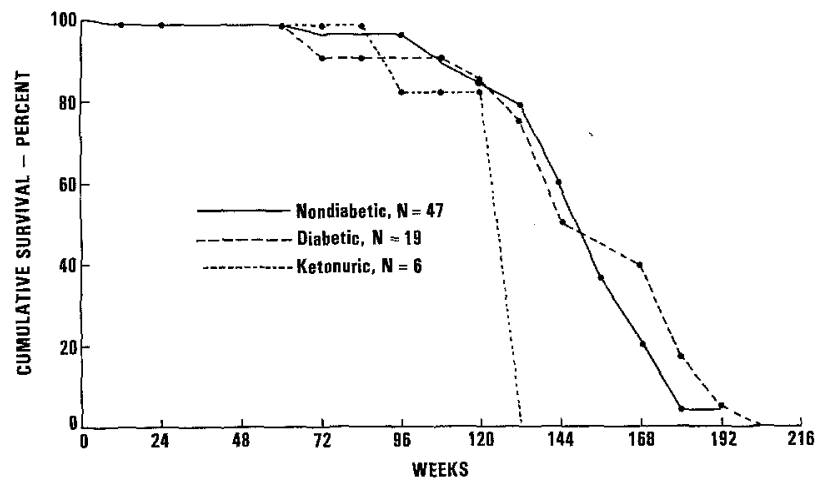

Fig. 6. Preliminary cumulative survival curves of female Chinese hamsters with diabetic parents

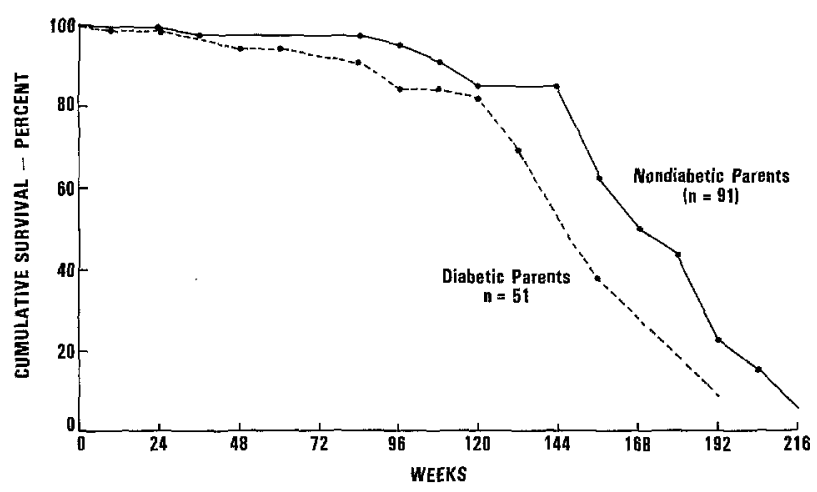

Fig. 7. Preliminary cumulative survival curves of nondiabetic male Chinese hamsters with diabetic or nondiabetic parents

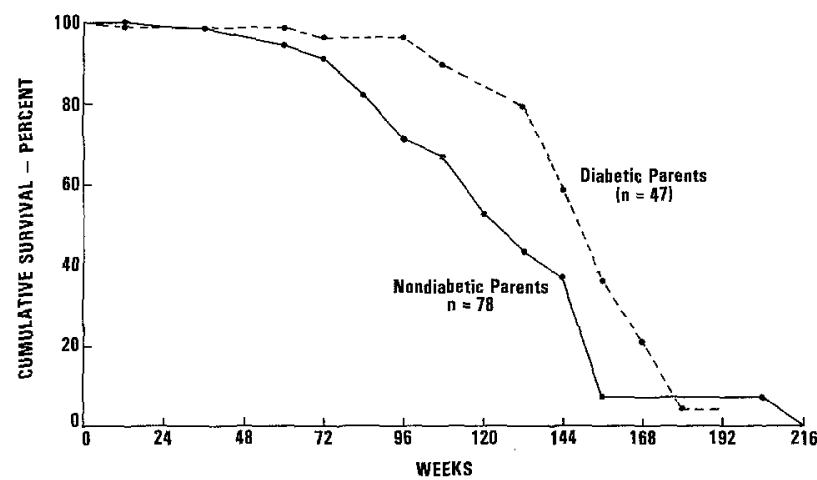

Fig. 8. Preliminary cumulative survival curves of nondiabetic female Chinese hamsters with diabetic or nondiabetic parents incidence of tumors. Urinary tract abnormality (UTA) was a common feature in animals which had presented with ketonuria. It was very often associated with marked distension of the bladder and with hydronephrosis which may have been the cause of death (Fig. 9). The incidence of UTA was very low in nondiabetics. The two nondiabetics from diabetic parents with UTA had tumors involving the urinary tract. Unfortunately, gross postmortem findings did not uncover specific abnormalities associated with mild diabetes. No obvious signs of vascular disease or myocardial infarction were evident in either diabetic or nondiabetic hamsters.

The ages listed in Table 5 indicate the mean age of animals that were examined post mortem $(35 \%$ of total) and do not, therefore, necessarily reflect the mean age of death for the various groups of hamsters.

An unexpected finding that came from crossing the highly inbred lines is presented in Table 6. Brothersister mating of inbred $\mathrm{Z}$ or $\mathrm{X}$ line animals resulted in a $65 \%$ and $78 \%$ incidence of diabetes, respectively, among their offspring. However, a hybrid cross between an inbred diabetic $\mathrm{X}$ with an inbred $\mathrm{Z}$ yields essentially no diabetics. The two offspring in the diabetic column, identified by the ?, had one positive test $(1+$ Testape) at 24 months of age. The other 29 never showed a positive test for glucosuria in over 50 tests per animal. Crosses of $X$ or $Z$ line animals with either L or XA line did not show anything remarkable with regard to incidence. However, onset time of diabetes in these hybrid offspring of $\mathrm{X}$ and $\mathrm{Z}$ to $\mathrm{L}$ was different (Fig. 10).

\section{Discussion}

The classification of animals in this study may seem rather arbitrary. However, it divided the population into quite homogeneous phenotypes since over $80 \%$ of diabetics showed consistently $4+$ glucosuria by Testape ${ }^{\circledR}$ after onset and $80 \%$ of the ketonuric hamsters exhibited consistently "large" for ketonuria, testing from onset on. Most animals defined as nondiabetic never had a positive test for glucosuria, while those which did generally had one positive test usually between $30-60$ days of age during the peak growth and food consumption period. It is recognized that some misclassification of very mild diabetics or chemical diabetics could have occurred.

A very important goal of this study was to acquire the capability to produce at any future time a population with similar genetic material to the one reported in this paper. This was achieved as breeders were selected from sublines in which the genes were essentially fixed in the homozygous state by inbreeding; only mutation is able to change such a genetic background.

The survival data show that life expectancy of males is more predictable than that of females (Fig. 5 
and 6 and Table 4). These observations are in agreement with observations in human diabetics $[25,26]$. Since the genes in both parents were essentially fixed in the homozygous state it seems reasonable that all siblings in a litter would have similar genotypes. Within a litter from two diabetic parents, however, animals defined as nondiabetic, diabetic and ketonuric phenotypes were observed. It is of considerable interest that
Furthermore, the data suggest that prevention or control of abnormal metabolism may increase longevity of the genetic diabetic male Chinese hamster. Thus a male Chinese hamster population with a similar genetic background to the one described may be very useful in the study of possible treatments for prevention or retardation of onset and severity of diabetes as well as for increased survival rates. The phenotypic hetero-

Table 4. Statistical significance of survival curves of Chinese hamsters which had an opportunity to live 3 years (born prior to March, 1971)

\begin{tabular}{llllllll}
\hline Type & Sex & No. & VS & Type & Sex & Number & Significance \\
\hline ND, NDP & M & 20 & & All, DP & M & 75 & $P<0.01$ \\
ND, NDP & M & 20 & & ND, DP & M & 40 & N.S. \\
ND, DP & M & 38 & & D, DP & M & 22 & N.S. \\
D, DP & M & 20 & & K, DP & M & 12 & $P<0.01$ \\
ND, NDP & F & 12 & All, DP & F & 50 & N.S. \\
ND, NDP & F & 12 & ND, DP & F & 27 & $P<0.01$ \\
ND, DP & F & 27 & D, DP & F & 18 & N.S. \\
D, DP & F & $\mathbf{1 6}$ & K, DP & F & 5 & $P<0.05$ \\
\hline
\end{tabular}

a Wilcoxon Test for significance

$\mathrm{ND}=$ Nondiabetic, NDP $=$ Nondiabetic parents, All $=$ Total population born to a parent type, $\mathrm{DP}=$ Diabetic parents, $\mathrm{D}=$ Diabetic, $\mathrm{K}=\mathrm{Ketonuric}$ diabetic

Table 5. Gross post mortem observations

\begin{tabular}{|c|c|c|c|c|c|c|c|}
\hline \multirow{3}{*}{$\begin{array}{l}\text { Parent } \\
\text { type }\end{array}$} & \multirow{3}{*}{$\begin{array}{l}\text { Type } \\
\text { offspring }\end{array}$} & \multirow{3}{*}{$\begin{array}{l}\text { Number } \\
\text { examined }\end{array}$} & \multicolumn{3}{|l|}{ Months } & \multirow{2}{*}{\multicolumn{2}{|c|}{ Per cent }} \\
\hline & & & \multirow{2}{*}{$\begin{array}{l}\text { Age at } \\
\text { death }\end{array}$} & \multicolumn{2}{|c|}{ Duration } & & \\
\hline & & & & Diab. & $\begin{array}{l}\text { Keton- } \\
\text { uric }\end{array}$ & $\begin{array}{l}\text { Abdominal } \\
\text { tumors }\end{array}$ & UTA $^{2}$ \\
\hline Nondiab. & Nondiab. & 12 & 38.4 & - & $\ldots$ & 50 & 8 \\
\hline Diab. & $\begin{array}{l}\text { Nondiab. } \\
\text { Diab. } \\
\text { Ketonuric }\end{array}$ & $\begin{array}{l}13 \\
19 \\
18\end{array}$ & $\begin{array}{l}28.7 \\
28.1 \\
23.2\end{array}$ & $\begin{array}{l}\overline{20.2} \\
22.1\end{array}$ & $\begin{array}{l}- \\
\overline{11.7}\end{array}$ & $\begin{array}{l}46 \\
50 \\
29\end{array}$ & $\begin{array}{l}15^{b} \\
40 \\
88\end{array}$ \\
\hline
\end{tabular}

a. UTA = Urinary tract abnormality

b Tumor involving UTA in both animals

Table 6. Incidence of diabetes in several inbred and hybrid crosses

\begin{tabular}{llcc} 
& & \multicolumn{2}{c}{ No. offspring and type } \\
\cline { 3 - 4 } Cross & Generation & Diabetics & Nondiabetics \\
\hline$Z \cdot Z$ & 8 and $9 \mathrm{a}$ & 97 & 53 \\
$\mathrm{X} \cdot \mathrm{X}$ & 9 and 10 & 42 & 12 \\
$\mathrm{X} \cdot \mathrm{Z}$ & F-1 hybrid & $2^{\mathrm{b}}$ & 29 \\
$\mathrm{X} \cdot \mathrm{L}$ & F-1 hybrid & 29 & 18 \\
$\mathrm{Z} \cdot \mathrm{L}$ & F-1 hybrid & 6 & 9 \\
$\mathrm{X} \cdot \mathrm{XA}$ & F-1 hybrid & 27 & 8 \\
$\mathrm{Z} \cdot \mathrm{XA}$ & F-I hybrid & 10 & 3 \\
\hline
\end{tabular}

a Number of continuous generations of brother-sister mating.

b These two animals had one single positive $(1+$ Testape) test for glucosuria at 24 months of age.

these males defined as nondiabetic with a genotype similar to their diabetic siblings lived almost as long as nondiabetics born to nondiabetic parents (Fig. 7). This observation suggests that it was abnormal metabolism, rather than genotype, that.contributed to the decreased survival rate of diabetic male Chinese hamsters. geneity within siblings with very similar genotypes again raises the question of what subtle factors are interacting with the genetic material to cause such heterogeneous phenotypes?

The data on the female population born to diabetic parents is at best puzzling and disconcerting. The incidence of diabetes is significantly lower than in their male siblings. The reason for this remains obscure but may have something to do with the lack of maternity in these females, as the stress of pregnancy can reveal abnormal glucose tolerance [27]. The survival data of females is even more disconcerting and difficult to understand. Diabetics failed to exhibit a shorter life span, and mild diabetics appeared to live longer than nondiabetics. However, there were too few animals in the study to reach unequivocal conclusions and animals which are currently one year old will have to be followed for at least two more years.

Another disconcerting finding was the lack of positive correlation between any of the parameters such as body weight, food consumption and those listed in Table 3, measured during the prediabetic 
phase, with eventual onset of diabetes. It has been previously reported that food consumption [28] and body weights $[29,30]$ are elevated in prediabetic Chinese hamsters. It should be pointed out, however, that prediabetics with hyperphagia probably had a different genotype since they were the offspring of inbred ketonuric parents which presumably have three homozygous recessive genes that cause glucosuria and ketonuria [31]. Hamsters in this study resulted from crossbreeding of parents whose diabetes was presumed to be due to two homozygous recessive genes $[32,33]$. Hyperphagic prediabetic Chinese hamsters were born from a ketonemic uterus [28-31], which was not true for the animals of this study.

Unfortunately, postmortem findings did not show a relationship between mild diabetes and a specific cause of death. This may in part be related to the very high incidence of abdominal tumors observed in aged

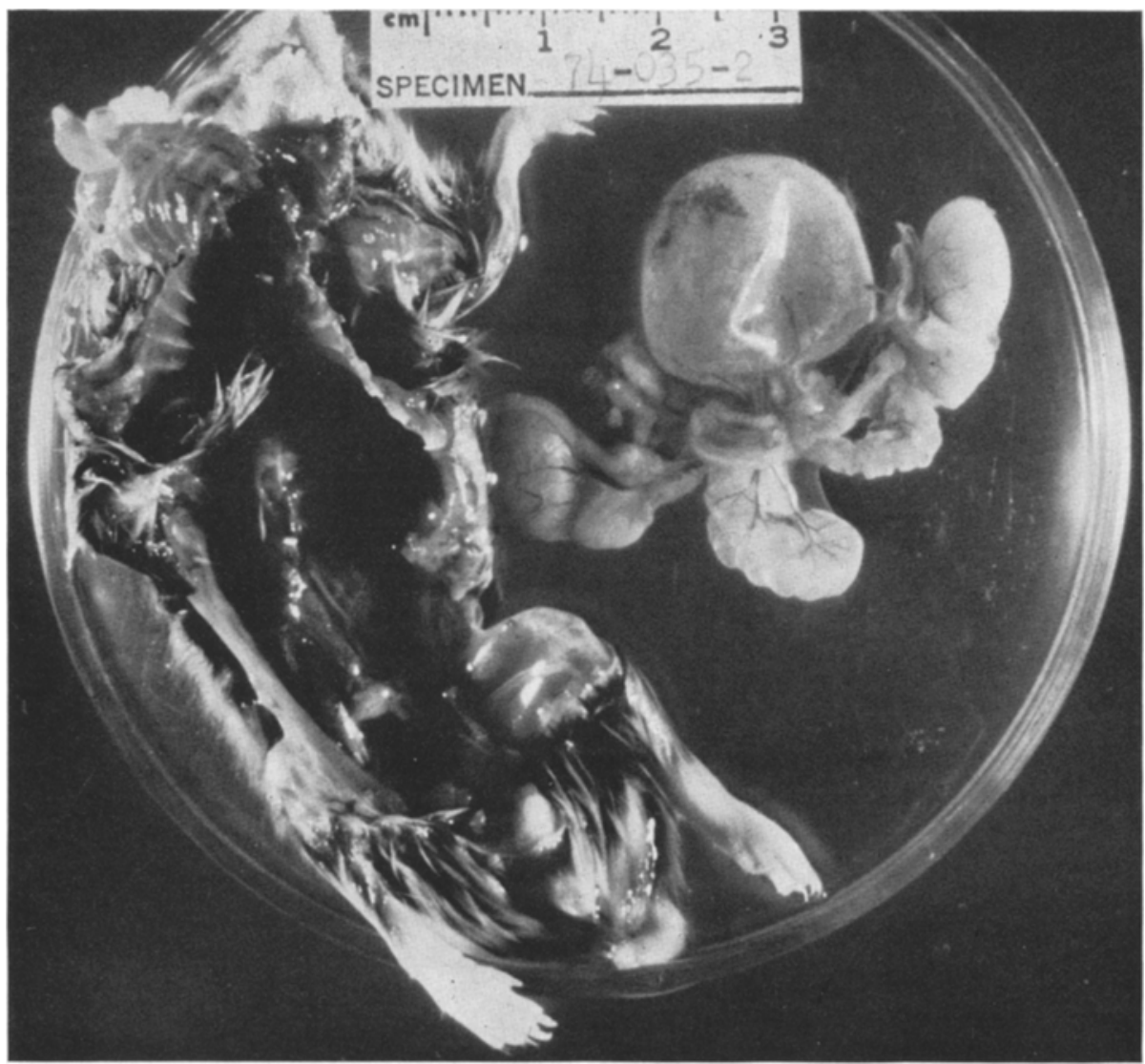

Fig. 9. Distended bladder in a ketonuric diabetic Chinese hamster

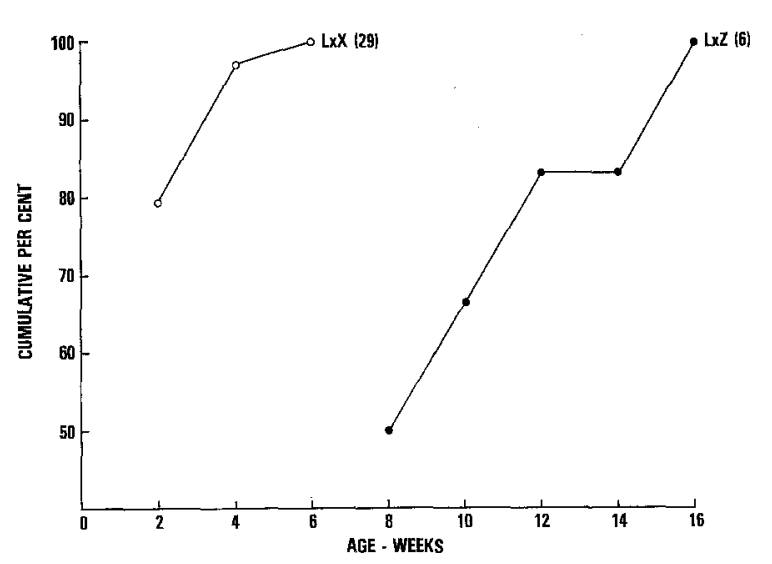

Fig. 10. Onset of diabetes in offspring from various crosses animals regardless of diabetes. It may be that mild diabetes does not influence survival in the Chinese hamster prior to two years of age, and, therefore, the probability is high that these diabetic animals will develop and succumb to tumors as nondiabetics do.

In the severe ketonuric diabetic, it is evident that the urinary system is affected to the extent that survival is influenced. The marked bladder distension observed in ketonurics is suggestive of the asymptomatic diabetic bladder syndrome of diabetic man [34, $35]$. In some cases, however the etiology may be related to pathologic involvement of the male reproductive system or neurological disturbances of the bladder. Kidney pathology per se cannot be excluded, as kidney disease has long been associated with diabetes in man [36]. 
One of the most important observations of this epidemiological study is the possibility that two diabetics from different inbred sublines can produce nondiabetic offspring. If the hypothesis is correct that diabetes in Chinese hamsters is due to two homozygous recessive genes $[32,33]$, then line $X$ and $Z$ cannot have more than one recessive gene for diabetes in common. It is theoretically possible that both diabetic genes in line $X$ and $Z$ are dissimilar. These concepts can and will be tested by inbreeding F.l's from the $\mathrm{X}$ to $\mathrm{Z}$ cross and by back-crossing F-1 females to their sire. The data on crosses of $\mathrm{X}$ and $\mathrm{Z}$ to other inbred sublines such as $\mathrm{L}$ suggest that there may be genetic differences between other inbred sublines too.

A long range goal of the Upjohn. Chinese hamster husbandry effort has been to segregate out, in inbred lines, individual diabetogenic genes fixed in the homozygous recessive state. It appears that this may be technically feasible by selective crossing between various diabetic and nondiabetic producing sublines. This is very important because it may be the only way to study parameters which are directly linked to a single diabetogenic gene. If this can be done it would be possible, by specific crosses, to produce animals with specific known diabetic genotypes.

In conclusion, populations of male Chinese hamsters can be produced which appear to be suitable to evaluate the effect of treatments on diabetes and longevity. At this point, females do not appear to be as promising a model, but this tentative conclusion could be reversed by additional data.

Evidence has been presented which suggest that diabetes in the Chinese hamster can be due to more than one combination of recessive genes.

Acknowledgement. The authors gratefully acknowledge the technical assistance of L.B. Needham, R. L. Miller, N.J. Smit, M.C. Blanks, R. Barnes, F. L. Schmidt, E.S. Cerda, W. Burr and E. Block.

\section{References}

1. Klimt, C.R., Knatterud, G.L., Meinert, C.L., Prout, T.E.: A study of the effects of hypoglycemic agents on vascular complications in patients with adult-onset diabetes. I design, methods and baseline results. Diabetes 19, (Suppl. II) $747-783(1970$ )

2. Meinert, C.L., Knatterud, G.L., Prout, T.E., Klimt, C.R.: A study of the effeets of hypoglycemic agents on vascular complications in patients with adult-onset diabetes. II Mortality results. Diabetes 19, (Suppl. II) $789-830(1970)$

3. Seltzer, H.S.: A summary of criticisms of the findings and conclusions of the university group diabetes program (UGDP). Diabetes 21, 976-979 (1972)

4. Feinstein, A.R.: Clinical biostatistics 8 . An analytical appraisal of the university group diabetes program study. Clin. Pharmacol. Ther. 12, 167-191 (1971)

5. Gerritsen, G.C., Dulin, W.E.: Characterization of diabetes in the Chinese hamster. Diabetologia 3, $74-84$ (1967)

6. Dulin, W.E., Gerritsen, G.C.: Interaction of genetics and environment on diabetes in the Chinese hamster as compared with human and other animal species. Acta diabet. lat. 9, (Suppl. 1) 48-84 (1972)

7. Gerritsen, G.C., Schultz, J.R., Johnson, M. A.: Preliminary analysis of incidence, onset of diabetes and survival rates of a genetically fixed reproducible population of Chinese hamsters. Diabetes 22, (Suppl. 1) $307(1973)$

8. Schmidt, F.L., Leslie, L.G., Schultz, J.R., Gerritsen, G.C.: Epidemiological studies of the Chinese hamster. Diabetologia 6, 154-157 (1970)

9. Federman, J.L., Gerritsen, G.C.: The retinal vasculature of the Chinese hamster: A preliminary study. Diabetologia 6, 186-191 (1970)

10. Soret, M.G., Dulin, W.E., Gerritsen, G.C.: Microangiopathy in animals with spontaneous diabetes. In: Early Diabetes, Suppl. 2, Advances in metabolic disorders. R. Camerini-Davalos, H.S. Cole (eds.) p. 291-298. New York and London: Academic Press 1973

11. Soret, M.G., Dulin, W.E., Mathews, J. Jr., Gerritsen, G.C.: Morphologic abnormalities observed in retina, pancreas and kidney of diabetic Chinese hamsters. Diabetologia 10, 567-579 (1974)

12. Shirai, T., Welsh, G.W., 3rd., Sims, E.A.H.: Diabetes mellitus in the Chinese hamster II. The evolution of renal glomerulopathy. Diabetologia 3, 266-286 (1967)

13. Conforti, A.: Ultrastruttura del rene nel diabete spontaneo dell'hamster Chinese (Cricetulus Griseus). Acta diabet. lat. 9, 655-687 (1972)

14. Luse, S.A., Gerritsen, G.C., Dulin, W.E.: Cerebral abnormalities in diabetes mellitus: An ultrastructural study of the brain in early onset diabetes mellitus in the Chinese hamster. Diabetologia 6, 192-198(1970)

15. Schlaepfer, W.A., Gerritsen, G.C., Dulin, W.E.: Segmental demyelination in the distal peripheral nerves of chronically diabetic Chinese hamsters. Diabetologia 10, $541-548(1974)$

16. Carpenter, A.-M., Gerritsen, G.C., Dulin, W.E., Lazarow, A.: Islet and beta cell volumes in diabetic Chinese hamster and their non-diabetic siblings. Diabetologia 3, 92-96 (1967)

17. Luse, S.A., Caramia, F., Gerritsen, G., Dulin, W.E.: Spontaneous diabetes mellitus in the Chinese hamster: An electron microscopic study of the islets of Langerhans. Diabetologia 3, 97-108 (1967)

18. Falconer, D.S.: The UFAW Handbook on the care and management of laboratory animals, 3rd Ed. Lane-Petter, W., Worden, A.N., Hill, B.F., Paterson, J.S., Vevers, H.G. (eds.) p. 82. Baltimore: The Williams and Wilkins Co. 1967

19. Riley, V.: Adaptation of orbital bleeding technique to rapid serial blood studies. Proc. Soc. exp. Biol. (N.Y.) 104, $751-754(1960)$

20. Hoffman, W.S.: A rapid photoelectric method for the determination of glucose in blood and urine. J. biol. Chem. 120, 51-55 (1937)

21. Cerda, E.S.: Personal communication (1970)

22. Barnes, R., Cerda, E.S., Johnson, M.: Personal communication (1972)

23. Cutter, S.J., Ederer. F.: Maximum utilization of the life table method in analyzing survival. J. chron. Dis. 8, $699-713$ (1958)

24. Bradley, J.: Distribution-free statistical tests, p. 388. Englewood Cliffs, New Jersey: Prentice-Hall, Inc. 1968

25. Kessler, I. I. : Mortality experience of diabetic patients. Amer. J. Med. 51, 715-724 (1971)

26. Garcia, M.J., McNamara, P.M., Tavia, G., Kannell, W.R.: Morbidity and mortality in diabetics in the Framingham population. Sixteen-year follow-up study Diabetes 23, 105-111 (1974) 
27. O'Sullivan, J.R.: Gestational diabetes. New Engl. J. Med. 264, 1082-1085 (1961)

28. Gerritsen, G.C., Blanks, M. C.: Preliminary studies on food and water consumption of prediabetic Chinese hamsters. Diabetologia 6, $177-179(1970)$

29. Gerritsen, G.C., Dulin, W.E. : Effect of diet restriction onset of development of diabetes in prediabetic Chinese hamsters. Acta diabet. lat. 9, (Suppl. 1) $597-613(1972)$

30. Gerritsen, G.C., Blanks, M.C., Miller, R.L., Dulin, W.E.: Effect of diet limitation on the development of diabetes in prediabetic Chinese hamsters. Diabetologia 10, $559-565$ (1974)

31. Gerritsen, G.C., Needham, L.B., Schmidt, F.T., Dulin, W.E.: Studies on the prediction and development of diabetes in offspring of diabetic Chinese hamsters. Diabetologia 6, 158-162 (1970)

32. Butler, L.: The inheritance of diabetes in the Chinese hamster. Diabetologia 3, 124-129 (1967)
33. Butler, I., Gerritsen, G.C.: A comparison of modes of inheritance of diabetes in the Chinese hamster and the KK mouse. Diabetologia 6, 163-167 (1970)

34. Ellenberg, M., Weber, H.: The incipient, asymptomatic diabetic bladder. Diabetes 16, 331 (1967)

35. Faerman, I., Maler, M., Jadzinsky, M.N., Fox, D., Alvarez, E., Zilverberg, J., Cibeira, J.B., Colinas, R.: Asymptomatic neurogenic bladder in juvenile diabetics. Diabetologia 7, 168 (1971)

36. Kimmelstill, P., Wilson, C.: Intercapillary lesions in the glomeruli of the kidney. Amer. J. Path. 12, 83-97 (1936)

Dr. George C. Gerritsen

Diabetes and Atherosclerosis

Research

The Upjohn Co.

Kalamazoo, Mi. 49001

USA 